\title{
CENTRAL NERVOUS SYSTEM EFFECTS OF BUPIVACAINE
}

\author{
W. Murray Robinson, and Leonard C. Jenkins
}

BUPIVACAINE HYDROCHLORIDE (1-n-butyl-DL-piperidine-2-carboxylic acid-2, 6 dimethylanilide) is one of the more recent amide-type local anaesthetics introduced into Canada. The main advantage of this agent over other amide-type local anaesthetics appears to be longer duration of action. ${ }^{1}$

The major clinical use of local anaesthetics is regional anaesthesia; however, these agents also have important effects on the cardiovascular system and on the central nervous system. The use of lidocaine to control ventricular dysrhythmias is an example. Several local anaesthetics have been used intravenously as adjuncts to general anaesthesia, ${ }^{2}$ for post-operative pain, and even for the treatment of rheumatoid arthritic pain. ${ }^{3}$ They have also been shown to act as central nervous system sedatives and anticonvulsants. ${ }^{4}$ Paradoxically, higher dosages of local anaesthetics produce generalized convulsions and, at even higher dosages, severe cardio-respiratory depression. ${ }^{5}$ These toxicities can occur during intravenous infusion, for example, in controlling cardiac dysrhythmias, ${ }^{6}$ or during regional anaesthesia.

A number of agents, including barbiturates and benzodiazepines, ${ }^{7-10}$ appreciably elevate the seizure threshold of local anaesthetics. It has recently been suggested that the threshold for lidocaine-induced seizures can be raised with diazepam without adding to the cardiovascular toxicity of the local anaesthetic. ${ }^{11}$

In view of the importance of the therapeutic and toxic effects of local anaesthetics on the central nervous and cardiovascular systems, this study is directed to examination of some of the central nervous system effects of bupivacaine and its concurrent effects on the cardiovascular system, with and without diazepam pretreatment.

\section{METHOD}

Five adult female cats weighing 3.0 to $3.6 \mathrm{~kg}$ were anaesthetized with an intraperitoneal injection of pentobarbitone $(35 \mathrm{mg} / \mathrm{kg})$. In order to implant E.E.G. (cortical and subcortical) electrodes, the head was clamped in a Kopf stereotaxic apparatus. A cortical screw was placed on the dura of the anterior and posterior surfaces of the sigmoid gyrus bilaterally, and four subcortical electrodes were placed according to Yamaguchi, Ling, and Marczynski's $\mathrm{s}^{12}$ modification of Jasper's stereotaxic atlas. ${ }^{13}$ The subcortical sites studied were the brain stem reticular formation, ventral posterolateral nucleus of the thalamus, medial amygdaloid nucleus, hippocampus and the anterior hypothalamus. The animals were allowed at least three weeks to recover from the surgery. At least five days were allowed to elapse between successive experiments. The accuracy of stereotaxic placement was later determined histologically.

From the Department of Anaesthesia Experimental Laboratory within the Department of Pharmacology, Faculty of Medicine, University of British Columbia. 
Before each experiment, the cat was given 70 per cent nitrous oxide and 30 per cent oxygen while the animal was in a restraining box. Decamethonium $(0.3 \mathrm{mg} /$ $\mathrm{kg}$ ) was given intramuscularly and the cat was intubated using a Portex paediatric tracheal tube and ventilated with a Palmer pump. A Sierra valve was used to control tidal volume. Gases from femoral arterial blood were measured with a Radiometer BM3 analyzer. An intravenous route was established using a 23-gauge needle in a forelimb vein.

Arterial pressure was measured from the femoral artery using a Statham P23PC transducer and recorded on a Grass Model 7 polygraph. Lead II of the electrocardiogram was recorded on the polygraph and on a Burdick electrocardiograph. The electroencephalogram was recorded on a Grass Model 6 electroencephalograph.

Bupivacaine was infused into all cats under varying conditions. The conditions were, pretreatment with diazepam ${ }^{*}(1 \mathrm{mg} / \mathrm{kg})$, normal saline $(0.2 \mathrm{ml} / \mathrm{kg})$, or diazepam solvent $\uparrow(0.2 \mathrm{ml} / \mathrm{kg})$. After the pretreatment had been given intravenously, the nitrous oxide/oxygen was discontinued and the animal was ventilated with air. The infusion of bupivacaine $(0.25 \mathrm{mg} / \mathrm{kg} / \mathrm{min}$ ) (Marcaine 0.5 per cent diluted to $1.25 \mathrm{mg} / \mathrm{ml}$ with saline) was started three minutes later using a Harvard infusion pump. The bupivacaine infusion was stopped as soon as generalized seizure activity developed. Three experiments using diazepam and three experiments using saline were done with each of the five cats. Two further experiments were done on each cat, one using saline and one using diazepam solvent as pretreatment, where the infusion of bupivacaine was continued beyond the seizure threshold to a total dose of $7.00 \mathrm{mg} / \mathrm{kg}$. The criterion for seizure threshold activity was taken to be bursts of high voltage spike activity appearing simultaneously and synchronously in all E.E.G. leads, lasting 3 seconds or longer and separated by periods of inactivity. The seizure threshold was determined for all three pretreated groups.

In animals pretreated with saline, the E.E.G. response to sensory stimulus was tested (that is, desynchronization of the E.E.G.). The stimulus used was a loud noise and, if there was no response observed on the E.E.G., a noxious electrical stimulus of 60 volts for $1 \mathrm{msec}$ was delivered subcutaneously. Also, in those animals which received saline pretreatment (except those where bupivacaine was continued beyond seizure threshold) diazepam $0.25 \mathrm{mg} / \mathrm{kg}$ was given intravenously as soon as generalized seizure activity occurred.

The animals recovered rapidly from each experiment and appeared to suffer no adverse effects.

\section{Results}

\section{(a) Effect of a Sensory Stimulus During Bupivacaine Infusion}

In all cats, a single sensory stimulus, noise or pain, changed the slow frequency

- Valium ${ }^{\circledR}$ Hoffmann-La Roche Inc. (diazepam $5 \mathrm{mg} / \mathrm{ml}$ dissolved in 40 per cent propylene glycol, 10 per cent ethanol, 5 per cent sodium benzoate, benzoic acid and 1.5 per cent benzyl alcohol).

†Diazepam solvent ( 40 per cent propylene glycol, 10 per cent ethanol, 5 per cent sodium benzoate, benzoic acid and 1.5 per cent benzyl alcohol). 


\section{BUPIVACAINE $\mathrm{mg} / \mathrm{kg}$}

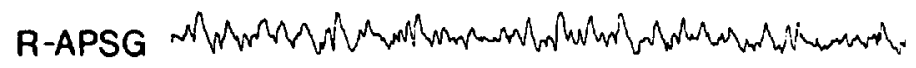

resting

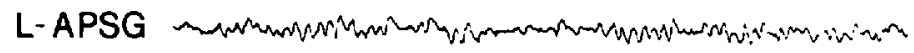

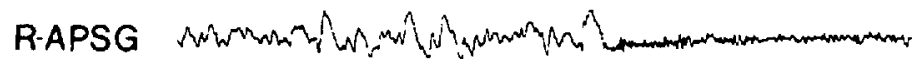

0

L-APSG

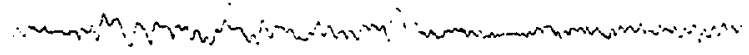

$\uparrow$

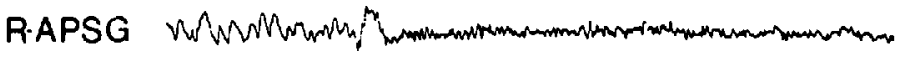

L-APSG

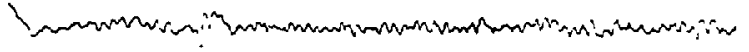

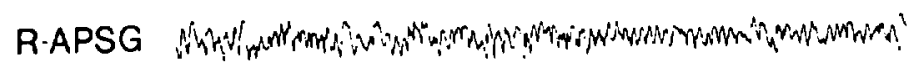

L-APSG

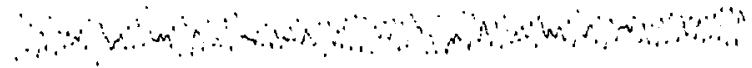

Figure 1. E.E.G. response to a sensory stimulus $(\uparrow$ ) (noise) during bupivacaine infusion. APSG, anterior-posterior sigmoid gyrus. Desynchronization of the cortical E.E.G. occurs after a sensory stimulus given at 0 and $1.0 \mathrm{mg} / \mathrm{kg}$ of bupivacaine. This response is blocked by 2.0 $\mathrm{mg} / \mathrm{kg}$ of bupivacaine.

high voltage cortical E.E.G. pattern, characteristic of the quiet resting cat, to a fast low voltage E.E.G. pattern (E.E.G. activation or desynchronization), which is typical of the conscious alert animal. Bupivacaine progressively blocked this response, first by decreasing the time interval from 50 seconds to 5 to 10 seconds between the sensory stimulus and return of the E.E.G. to a synchronous or deactivated pattern. At a higher dosage (mean \pm S.D. $=2.0 \pm 0.39 \mathrm{mg} / \mathrm{kg}$ ) there was no E.E.G. desynchronization when a single sensory stimulus was given (Figure 1). 
R-APSG

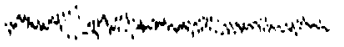

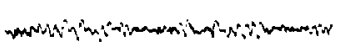

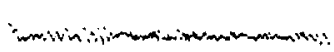

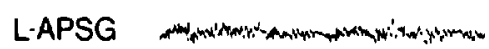

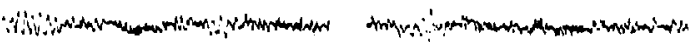

R-Am

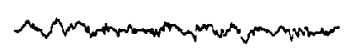

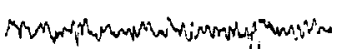

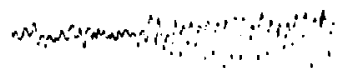

L-Am

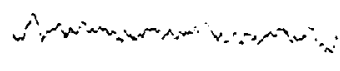

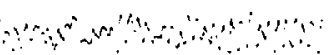

R-Hipp
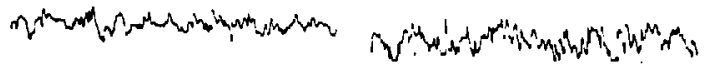

d4.

L-Hipp

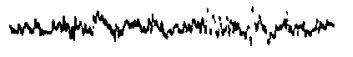

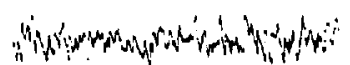

$1.9 \mathrm{mg} / \mathrm{kg}$

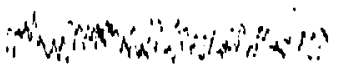

$2.2 \mathrm{mg} / \mathrm{kg}$

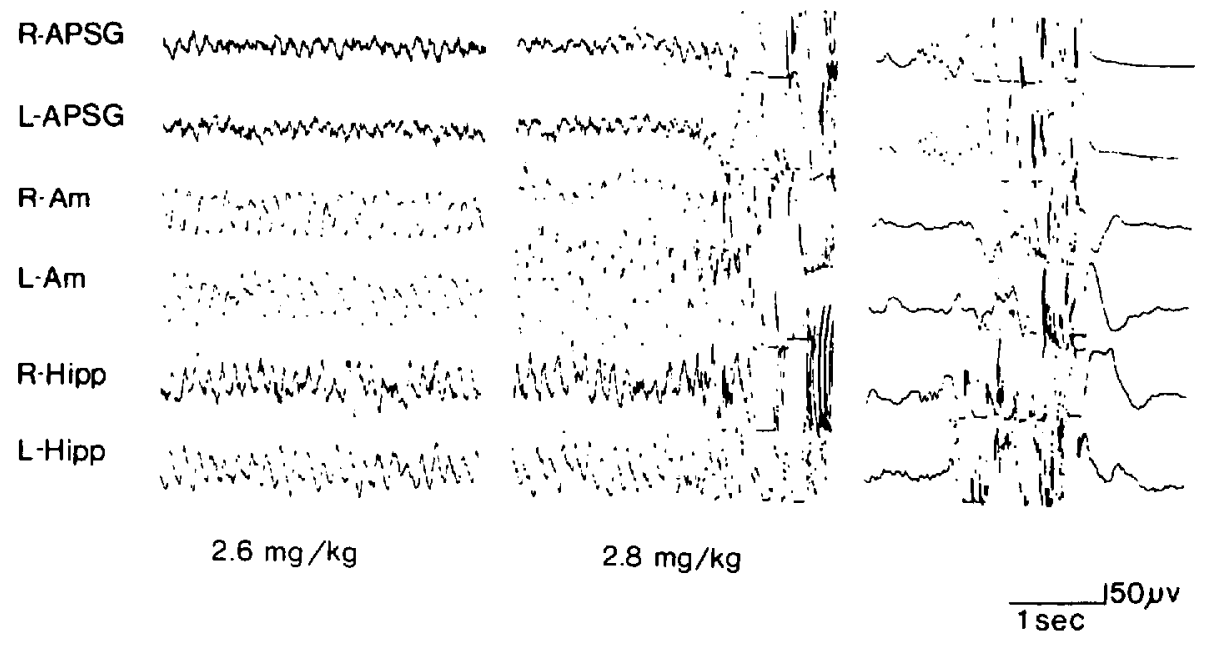

Figure 2. Cortical and subcortical E.E.G. activity during bupivacaine infusion. APSG, anterior-posterior sigmoid gyrus. Am, medial amygdaloid nucleus. Hipp, hippocampus. Note the rhythmic waves, appearing first in the left and later right medial amygdaloid nucleus, then in the right and left hippocampus, and later developing into generalized seizure activity.

\section{(b) Subcortical E.E.G. Changes During Bupivacaine Infusion}

The most obvious electrical change that occurred during bupivacaine infusion consisted of rhythmic high voltage (75 $\mu \mathrm{V}, 9-10$ cycles per sec) waves, usually appearing first in the amygdala and later in the hippocampus. Occasionally this activity appeared simultaneously in the hippocampus and amygdala. These waves remained rhythmic, but increased in amplitude to 200 to $250 \mu \mathrm{V}$ and the frequency slowed to 7 cycles per second as the bupivacaine infusion continued. These rhythmic waves did not appear in the other subcortical leads. This activity then proceeded to develop into generalized seizure activity (Figure 2 ). The generalized seizure activity lasted 3 to 5 minutes once the bupivacaine infusion was stopped. In all animals receiving saline pretreatment ( 5 animals, 15 experiments), diazepam $0.25 \mathrm{mg} / \mathrm{kg}$ intravenously terminated seizure activity caused by bupivacaine. The time required to terminate seizure activity was from 15 to $45 \mathrm{sec}$. 
TABLE I

Seizure Threshold for Bupivacaine $(\mathrm{mg} / \mathrm{kg}$ )

\begin{tabular}{cccc}
\hline & \multicolumn{3}{c}{ pretreatment } \\
\cline { 2 - 4 } cat number & saline only & solvent only & diazepam + solvent \\
\hline 1 & 3.02 & 3.13 & 6.41 \\
2 & 2.20 & 3.75 & 7.19 \\
3 & 2.58 & 3.92 & 7.41 \\
4 & 3.52 & 3.33 & 7.04 \\
5 & 2.87 & 3.67 & 6.93 \\
mean \pm S.D. & $2.84 \pm 0.49$ & $3.56 \pm 0.32$ & $7.00 \pm 0.37$ \\
\hline
\end{tabular}

\section{Bupivacaine}

$\mathrm{mg} / \mathrm{kg}$

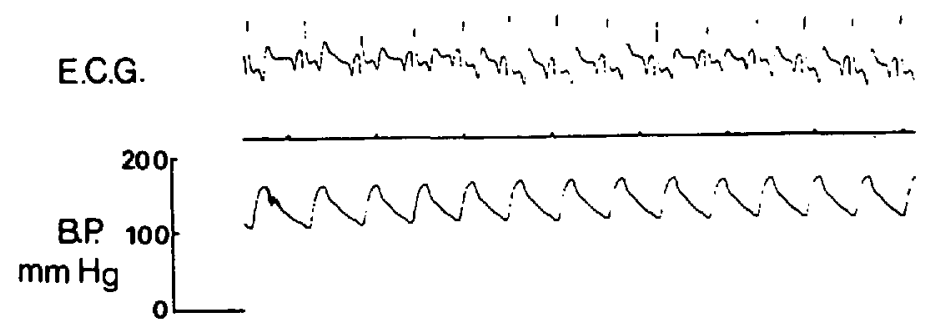

control
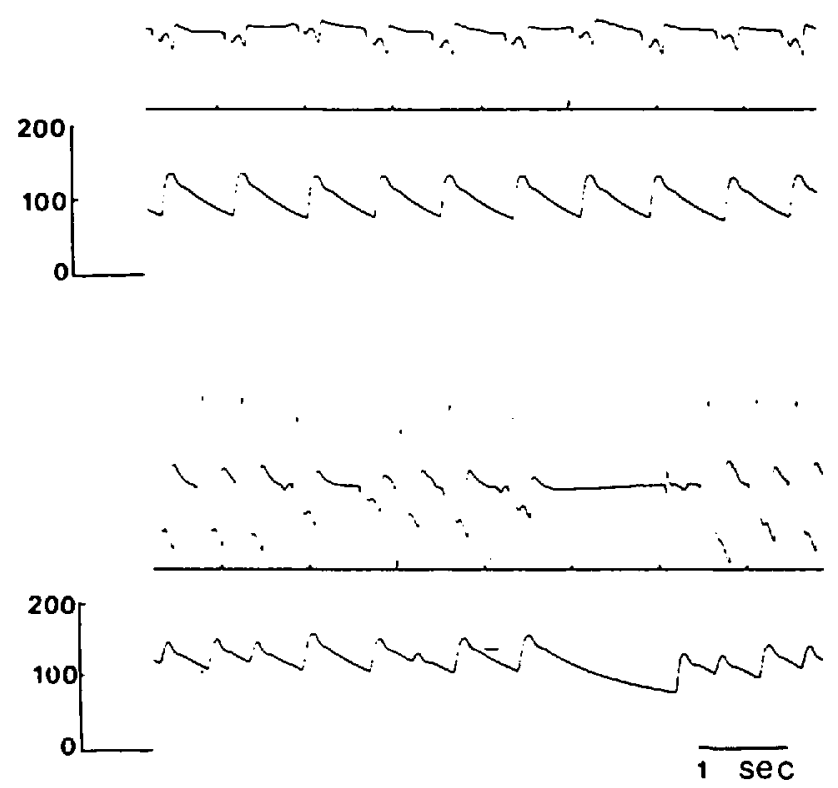

Figuhe 3. Arterial pressure during bupivacaine infusion following diazepam (Valium ${ }^{\circledR}$ ), pretreatment. Note junctional rhythm at $3.5 \mathrm{mg}$ and at $5.5 \mathrm{mg}$ junctional rhythm and sinus arrest. 
(c) Seizure Threshold ( $\mathrm{mg} / \mathrm{kg}$ )

In the group pretreated with saline the mean seizure threshold dosage of bupivacaine was $2.84 \pm 0.49$. The seizure threshold was higher than this in 4 out of 5 animals pretreated with diazepam solvent. Pretreatment with diazepam raised the seizure threshold to $7.00 \pm 0.14$. Individual values for each cat are shown in Table I. This difference between saline and diazepam is statistically significant; $\mathrm{p}<0.001$ using the paired Student $\mathrm{t}$ test.

\section{(d) Cardiovascular Changes}

Arterial pressure. There were no significant changes in arterial pressure during bupivacaine infusion, up to $7.0 \mathrm{mg} / \mathrm{kg}$, regardless of what pretreatment was used. Diazepam alone, or diazepam solvent alone had no effect on the arterial pressure (Figure 3).

Electrocardiogram. Neither diazepam alone, nor diazepam solvent alone produced any changes in the electrocardiogram. Changes that occurred in the E.K.G. of the group pretreated with saline during bupivacain infusion were slowing of the rate from 156 to 100 , increased P-R interval, increased QRS interval, increased QT interval; peaked T waves and non-specific ST-T changes. Some of these changes are shown in Figure 4. A brief episode of junctional rhythm occurred at the onset of generalized seizure activity during one experiment with one cat. There were no other dysrhythmias, even when $7.00 \mathrm{mg} / \mathrm{kg}$ of bupivacaine was given.

Cats pretreated with diazepam or diazepam solvent all developed cardiac dysrhythmias (Figures 5 and 6 ) during the bupivacaine infusion. The mean dose of bupivacaine $(\mathrm{mg} / \mathrm{kg})$ at the onset of dysrhythmias in the diazepam pretreated group was $3.14 \pm 1.02$. This dosage was lower in four out of five cats pretreated with solvent (mean \pm S.D. $=2.71 \pm 0.89$ ). Individual values are shown in Table II.

The cardiac dysrhythmias seen in these two groups were sinus arrest, junctional escape beats, and junctional rhythm in all cats. Fusion beats, ventricular premature beats and episodes of ventricular tachycardia were seen in three cats. Increased P-R interval, QRS interval, increased QT interval, augmentation of the amplitude of the $Q R$ and $S$ waves, peaked $T$ waves, shift of the electrical axis and non-specific ST-T changes were also seen. There were no episodes of ventricular fibrillation and no fatalities. The electrocardiographic changes were reversed approximately 10 minutes after discontinuing bupivacaine. These changes in the electrocardiogram were not altered during generalized seizure activity.

\section{Discussion}

\section{(a) Effect of a Sensory Stimulus During Bupivacaine Infusion}

These results show that bupivacaine progressively blocked the cortical electroencephalogram response to a sensory stimulus. Desynchronization of the E.E.G. occurred at low dosage, but the time interval to the return of a synchronized pattern was reduced from a control of 50 seconds to between 5 and 10 seconds. At a higher dosage (mean \pm S.D. $=2.00 \pm 0.39 \mathrm{mg} / \mathrm{kg}$ ), no desynchronization occurred in response to a sensory stimulus. The interpretation of these results is difficult and 


\section{Bupivacaine $\mathrm{mg} / \mathrm{kg}$}

\section{lead II}
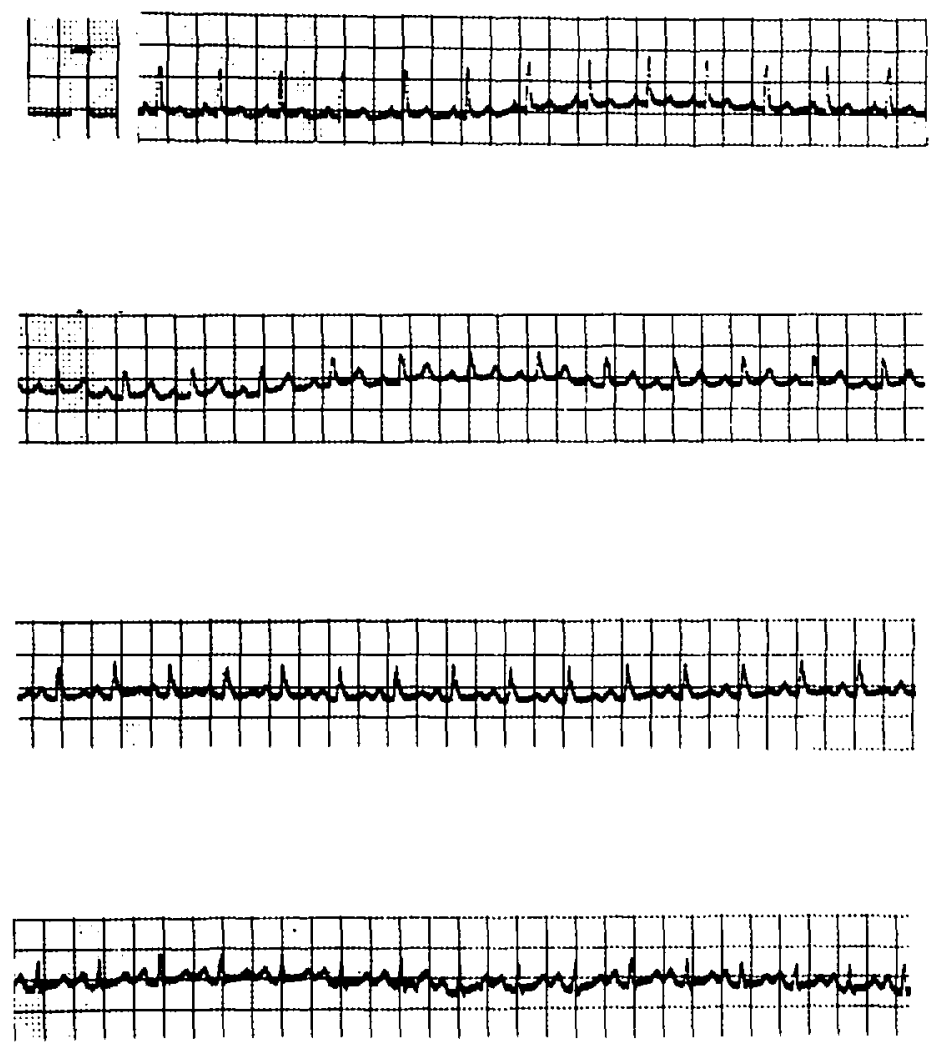

Figure 4. E.K.G. effects of bupivacaine infusion after pretreatment with saline. Sinus rhythm is evident at all dosages.

open to discussion. The observed blockade of the E.E.G. response may represent sedation and/or analgesia. Local anaesthetics have been used intravenously as analgesics, sedatives and anticonvulsants, ${ }^{2-4}$ but have not gained widespread acceptance because of a low therapeutic index. If this blockade of the E.E.G. response is analgesia or sedation, it occurs at a dose close to the seizure threshold. It has been reported that pre-seizure central depression following bupivacaine infusion is less severe than with lidocaine, suggesting that bupivacaine probably offers no advantage over lidocaine when used systematically as an analgesic or a sedative.

(b) Subcortical E.E.G. Changes During Bupivacaine Infusion

The results show that the earliest and most obvious alterations in spontaneous cerebral activity with bupivacaine occurred in the amygdala. Usually later, but occasionally simultaneously, this effect appeared in the hippocampus. This seems 
lead II
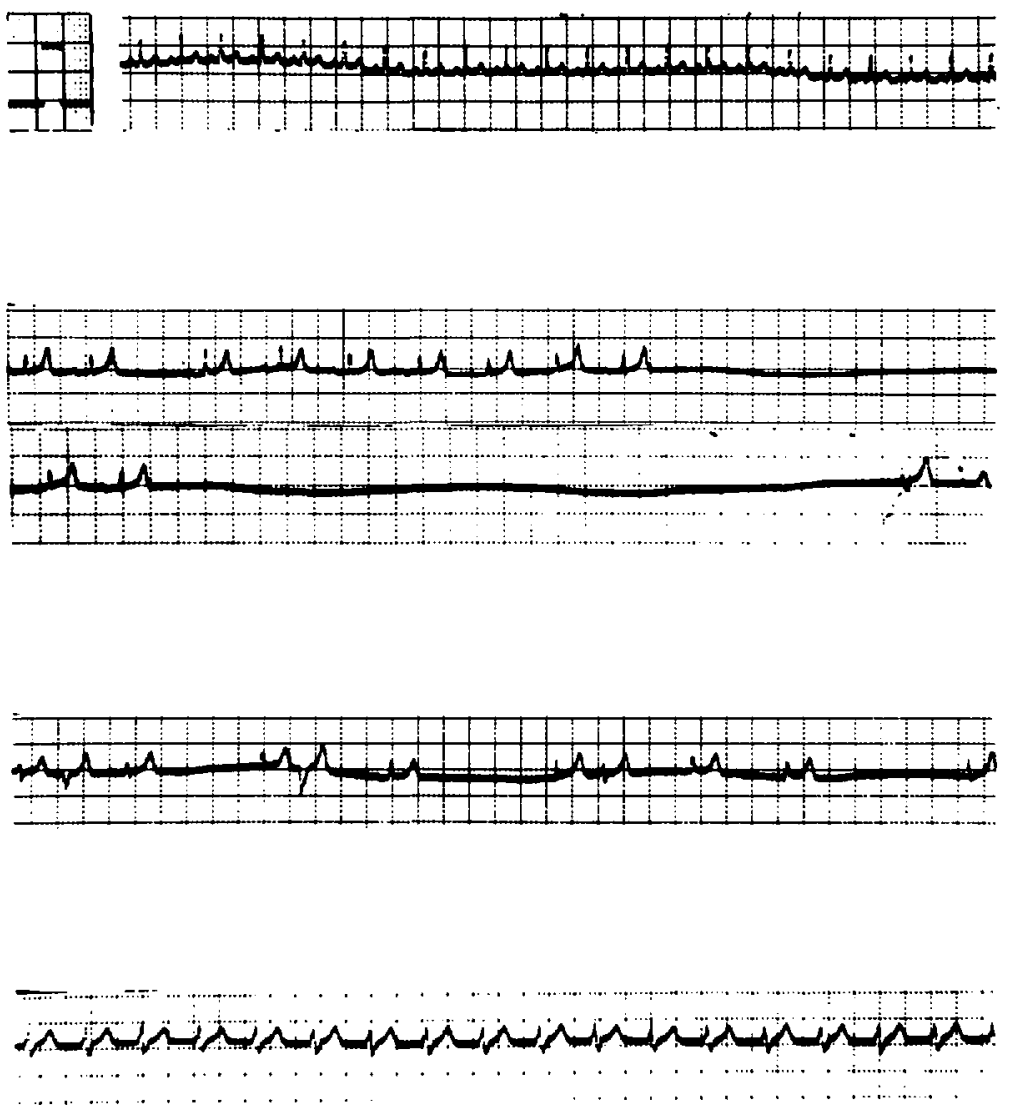

FIGURE 5. E.K.G. effects of bupivacaine infusion following diazepam (Valium(1)) pretreatment. $0 \mathrm{mg} / \mathrm{kg}=$ sinus rhythm; $2.7 \mathrm{mg} / \mathrm{kg}=$ long periods of sinus arrest with junctional escape beats; $3.3 \mathrm{mg} / \mathrm{kg}=$ sinus arrest, junctional escape beats, and one premature ventricular beat; $5.6=$ junctional rhythm.

to be a dose-dependent phenomenon and, when a high enough cumulative dosage is reached, seizures develop. Wagman, de Jong, and Prince ${ }^{14}$ have described similar amygdaloid rhythmic activity in the cat when lidocaine was administered. Lidocaine, prilocaine, mepivacaine and bupivacaine ${ }^{15}$ do not appear to produce this activity in Rhesus monkeys. It would appear that bupivacaine produces subcortical changes similar to lidocaine. These changes are similar to those obtained in cats by Preston when he used high doses of chlorpromazine. ${ }^{16}$ Whether these focal amygdaloid discharges are due to direct excitation or to release of inhibition $^{17}$ by local anaesthetics, or to some other mechanism requires further study.

(c) Seizure Threshold and Treatment of Seizures

The most frequent, although relatively rare, systemic toxic effect of local anaes- 


\section{Bupivacaine $\mathrm{mg} / \mathrm{kg}$}

lead \|
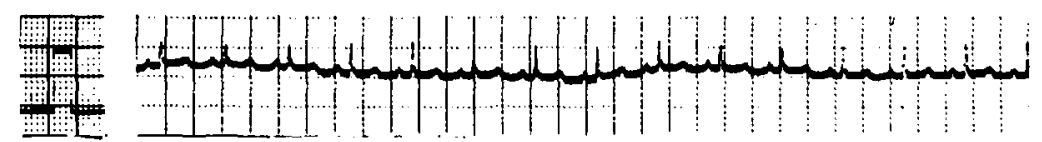

0
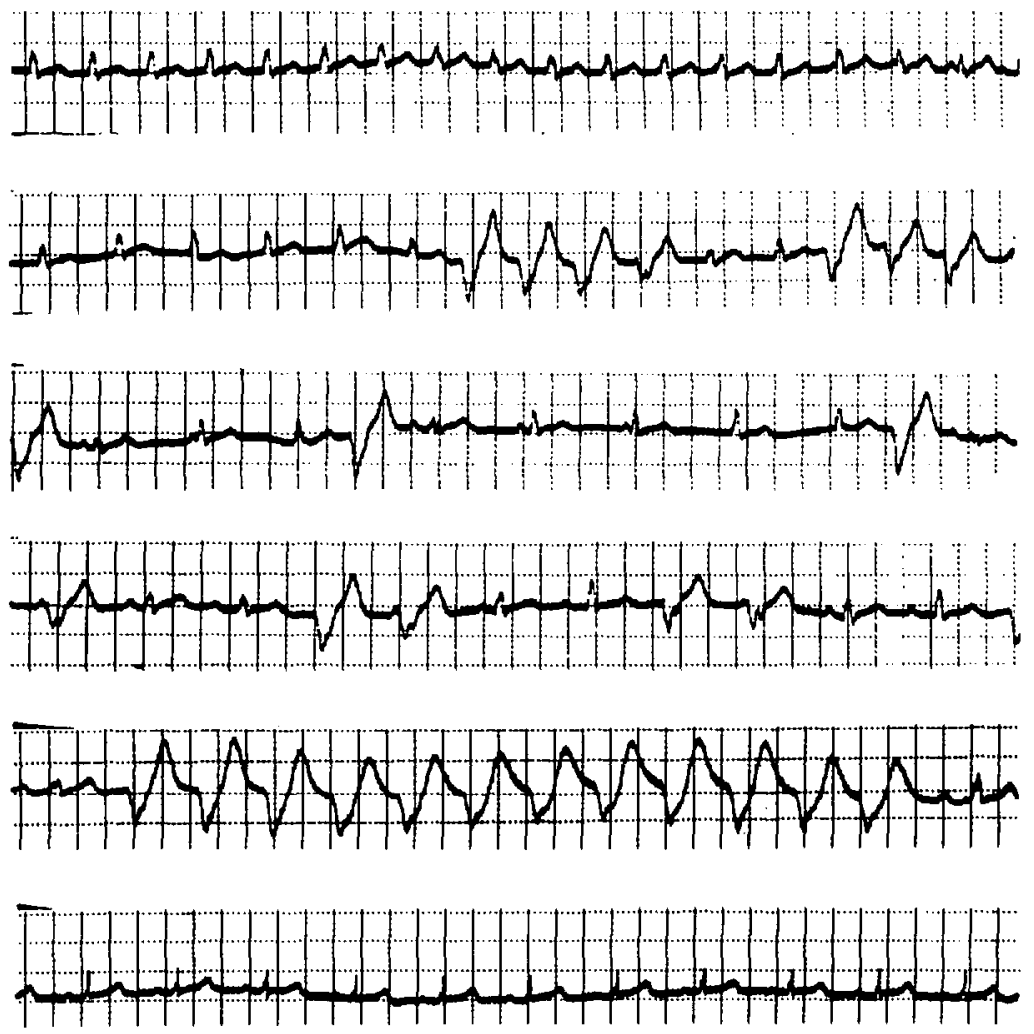

Figure 6. E.K.G. effects of bupivacaine infusion following diazepam (Valium ${ }^{\circledR}$ ) pretreatment. $0 \mathrm{mg} / \mathrm{kg}=$ sinus rhythm; $2.4 \mathrm{mg} / \mathrm{kg}=$ junctional $\mathrm{rhythm}$, sinus $\mathrm{rhythm} ; 3.3 \mathrm{mg} / \mathrm{kg}=$ junctional rhythm with runs of ventricular premature beats; $3.6 \mathrm{mg} / \mathrm{kg}=$ sinus beats, ventricular premature beats, fusion beats and junctional beats; $5.1 \mathrm{mg} / \mathrm{kg}=$ sinus beats and ventricular premature beats; $7.0 \mathrm{mg} / \mathrm{kg}$ ventricular tachycardia. Sinus rhythm returned (bottom trace) 10 minutes after the bupivacaine was stopped.

thetics is generalized seizures. Diazepam has been shown to raise the seizure threshold for lidocaine, procaine, tetracaine and cocaine-induced seizures. ${ }^{7-9}$ Diazepam has also been demonstrated to abolish seizures resulting from lidocaine ${ }^{18}$ and procaine. ${ }^{7}$ Our observations show that diazepam is also effective in raising the seizue threshold for bupivacaine seizures and in the treatment of bupivacaine seizures. The mean seizure threshold dose was raised by diazepam to a mean \pm S.D. of $7.00 \pm 0.14$ from $2.48 \pm 0.49$. This is similar to the two-fold increase 
ROBINSON \& JENKINS: CENTRAL NERVOUS SYSTEM

TABLE II

Minimal Dysrhythmic Dosage of Bupivacaine $(\mathrm{mg} / \mathrm{kg}$ )

\begin{tabular}{cccc}
\hline & \multicolumn{3}{c}{ pretreatment } \\
\cline { 2 - 4 } cat number & saline only & solvent only & diazepam + solvent \\
\hline 1 & $>7.00$ & 2.25 & 2.07 \\
2 & $>7.00$ & 3.75 & 4.10 \\
3 & $>7.00$ & 3.57 & 4.30 \\
4 & $>7.00$ & 1.75 & 2.28 \\
5 & $>7.00$ & 2.25 & 2.97 \\
mean \pm S.D. & $>7.00$ & $2.71 \pm 0.89$ & $3.14 \pm 0.97$ \\
\hline
\end{tabular}

in threshold observed for lidocaine and diazepam by de Jong and Heavner. ${ }^{10}$ Diazepam stopped bupivacaine seizure activity in 15 to 45 seconds, which is not unlike Munson and Wagman's ${ }^{18}$ observation with lidocaine. Diazepam solvent also significantly raised the seizure threshold in four of five cats. This is expected since the solvent contains 10 per cent ethanol. The question of the mechanism of these effects is considered elsewhere. ${ }^{7,18}$ Even though diazepam is useful in treating bupivacaine seizure activity, this is seldom necessary when adequate ventilation and oxygenation are ensured because these seizures are of short duration. Likewise, it may not be reasonable to pretreat patients with diazepam in order to raise the bupivacaine seizure threshold because of possibly enhanced cardiovascular toxicity which may result from these two drugs together.

\section{(d) Cardiovascular Effects}

These experiments indicate that pretreatment with diazepam or diazepam solvent of animals receiving bupivacaine results in obvious dysrhythmias. Bupivacaine alone produced electrocardiogram changes similar to those described for lidocaine. ${ }^{9,19}$ No dysrhythmias resulted from bupivacaine, diazepam, or diazepam solvent when given alone. de Jong and Heavner ${ }^{11}$ did not find any increased cardiovascular toxicity when diazepam was used to raise the threshold of lidocaine seizures. They used diazepam $0.25 \mathrm{mg} / \mathrm{kg}$ intramuscularly one hour prior to a single bolus injection of lidocaine. This bolus resulted in severe hypotension and cardiac dysrhythmias in both pretreated and non-pretreated animals. de Jong and Heavner concluded that diazepam did not add to the cardiovascular toxicity of lidocaine.

A compound related to diazepam, chlordiazepoxide,$^{20}$ has recently been shown, in cats, to be an effective treatment for ventricular dysrhythmias induced by coronary artery occlusion and digitalis. Diazepam (Valium ${ }^{*}$ ), however, has previously been found ineffective in the treatment of dysrhythmias. ${ }^{21}$ Our results show that animals pretreated with diazepam solvent developed dysrhythmias similar to those treated with diazepam and that the onset of dysrhythmias occurred earlier in four of the five cats treated with diazepam solvent. Louis, ${ }^{22}$ using cats, has shown that 40 per cent propylene glycol alone or with 10 per cent ethanol produces cardiac dysrhythmias similar to the dysrhythmias we saw. His dosages, however, were three to five times larger than those used in our experiments. It is probable that the dysrhythmias we observed were due to a combined effect of propylene glycol and bupivacaine. It may also be that diazepam, like chlordiaze- 
poxide, does in fact have antidysrhythmic properties and that this is obscured by the effects of the solvent. The clinical significance of this requires further study. The dosage of diazepam we used is higher than that normally used clinically in man; however, it is difficult to extrapolate drug dosage from one species to another. It is conceivable that this solvent could increase the chance of developing a serious dysrhythmia in some patients, for example those with cardiac disease, hypoxia, hypercapnia, or in the presence of other dysrhythmogenic drugs, and that the physician should be aware of this possibility.

\section{SumMary}

The central nervous system and concurrent cardiovascular effects of bupivacaine infusion were studied in cats. It was possible to block cortical E.E.G. desynchronization resulting from a sensory stimulus with bupivacaine. The earliest subcortical change that occurred was rhythmic activity in the amygdala and later in the hippocampus. Occasionally, this activity appeared simultaneously in both these sites. Diazepam pretreatment raised the seizure threshold of bupivacaine. Diazepam was also effective in terminating established seizure activity resulting from bupivacaine. All animals pretreated with diazepam (Valium ${ }^{8}$ ) or diazepam solvent developed cardiac dysrhythmias during bupivacaine infusion. The possible clinical significance of the interaction of bupivacaine and diazepam solvent is considered.

\section{RÉSUMÉ}

Nous avons étudié les effets d'une perfusion de Bupivacaïne sur les systèmes nerveux et cardio-vasculaire du chat.

La Bupivacaïne est capable de prévenir sur l'électro-encéphalogramme cortical, l'apparition de la désynchronisation qui suit normalement une stimulation sensorielle.

Au niveau sous-cortical, les changements les plus précoces, (activités rythmiques), se manifestent d'abord à l'amygdale, ensuite à l'hippocampe, quelques fois aux 2 endroits en même temps. Le Diazepam administré préventivement élève le seuil commitial de Bupivacaine et est aussi capable d'inhiber les manifestations convulsives induites par celle-ci.

Tous les animaux prétraités au Diazepam ou à son solvant, ont présenté des arythmies durant la perfusion de Bupivacaïne.

La signification clinique de cette interaction médicamenteuse est discutée dans l'article.

\section{ACKNOWLEDGMENT}

We would like to thank Miss C. Bruce for technical assistance and Dr. K.M. Leighton, Dr. M.C. Sutter, Dr. H.D. Sanders and Dr. B.A. Saunders for advice in preparing this manuscript.

This work was in part financed by grants-in-aid from the Burroughs Wellcome Company (Canada) and Poulenc Limited of Montreal. 


\section{REFERENCES}

1. Moone, D., Bridenbaugh, L.O., Bridenbaugh, P.O., \& Thompson, G.E. Bupivacaine HCl: a summary of investigational use in 3274 cases. Anaesth. Analg. 50: 856 (1971).

2. Phillips, D.C. Intravenous lidocaine as adjunct to general anaesthesia: a clinical evaluation. Anesth. Analg. 39: 317 (1960).

3. Graubard, D.J. \& Peterson, M.C. Clinical uses of intravenous procaine. Springfield: Charles C. Thomas, 1950.

4. Berry, C.A., SANNer, J.H., \& Keasling, H.H. A comparison of the anticonvulsant activity of mepivacaine and lidocaine. J. Pharmacol. Exp. Ther. 133: 357 ( 1961 ).

5. Steinhaus, J.E. Local anesthetic toxiçity: a pharmacological re-evaluation. Anesthesiology 18: 275 (1957).

6. Crampton, R.S. \& Oriscello, R.G. Petit and grand mal convulsions during lidocaine hydrochloride treatment of ventricular tachycardia. J.A.M.A. 204: 201 ( 1968).

7. Feinstejn, M.B., Lenard, W., \& Mathias, I. The antagonism of local anaesthetic-induced convulsions by the benzodiazepine derivative diazepam. Arch. Int. Pharmacodyn 187: 144 (1970).

8. Aldrete, J.A. \& Daniel, W. Evaluation of premedicants as protective agents against convulsive $\left(\mathrm{LD}_{50}\right)$ doses of local anaesthetics in rats. Anesth. Analg. 50: 127 (1971).

9. Eidelberg, E., NeEr, H.M., \& Miller, M.K. Anticonvulsant properties of some benrodiazepine derivatives. Neurology 15: 223 (1965).

10. de Jong, R.H. \& Heavner, J.E. Diazepam prevents local anesthetic seizures. Anesthesiology 34: 523 (1971).

11. De Jong, R.H. \& Heavner, J.E. Diazepam and lidocaine-induced cardiovascular changes. Anesthesiology 39: 6.33 (1973).

12. Yamaguchi, N., Linc, G.M., \& Marczynski, T.J. Recruiting responses observed during wakefulness and sleep in unanaesthetized chronic cats E.E.G. Clin. Neurophysiol. 17: 246 (1964).

13. Jasper, H.H. \& Ajmone-Mansan, C. A stereotaxic atlas of the diencephalon of the cat. National Research Council of Canada, 1956.

14. Wagman, I.H., DE Jong, R.H., \& Prince, D.A. Effects of lidocaine as spontaneous cortical and subcortical electrical activity. Arch. Neurol. 18: 277 (1968).

15. Munson, E.E., Martucci, R.W., \& Wagman, I.H. Bupivacaine and lignocaine-induced seizures in rhesus monkeys. Brit. J. Anaesth. 44: 1025 (1972).

16. Preston, J.B. Effects of chlorpromazine on the central nervous system of the cat: a possible neural basis for action. J. Pharmacol. Exp. Ther. 118: 100 (1956).

17. Frank, G.B. \& Sandens, H.D. A proposed common mechanism of action for general and local anaesthetics on the central nervous system. Brit. J. Pharmacol. $21 ; 1$ ( 1963).

18. Munson, E.S. \& Wagman, I.H. Diazepam treatment of local anaesthetic-induced seizures. Anesthesiology 37: 523 (1972).

19. Lieberman, N.A., Harris, R.S., Katz, R.I., Lipschutz, H.M., Dolgin, M., \& Fisher, V.J The effects of lidocaine on the electrical and mechanical activity of the heart. Am. J. Cardio. 22: 375 (1968).

20. Giliss, R.A., Thibodeaux, H., \& Bahr, L. Antiarrhythmic properties of chlordia-epoxide. Circulation 49: 272 ( 1972 ).

21. Nevins, M.A., Mattes, L.M., Spritzer, R.C., Weizenseel, A.C., Donoso, E., \& Friedberg, C.K. Ineffectiveness of diazepam as an antiarrhythmic agent. J. Mt. Sinai Hosp. 36: 408 ( 1969 )

22. Louis, S., KutT, H., \& McDowell, F. The cardiovascular changes caused by intravenous dilantin and its solvent. Amer. Heart. J. 74: 523 (1968). 